\title{
The prevalence and mortality in Hospitalised Patients with Mild, Moderate and Severe Hyponatremia
}

\author{
Jayadave Shakher, Nirav Gandhi, Lisa Shepherd, Christopher Pitt \& Kamalfit Chatha \\ Heart of England NHS Trust, Birmingham, West Midlands, UK.
}

\section{Introduction:}

Hyonatraemia, defined as serum sodium $<135 \mathrm{mmol} / \mathrm{L}$ is the commonest electrolyte abnormality, especially amongst hospitalised patients and is associated with increased length of stay, morbidity and mortality.

\section{Aim:}

To determine the prevalence of mild, moderate and severe Hyponatraemia in the hospitalised patients and estimate mortality between these three groups and compared against Normonatraemic group.

\section{Methods:}

This is an observational retrospective audit in patients admitted to Acute Hospital Trust across 3 sites from July 2010 to July 2011. The data are obtained from hospital clinical laboratory and patients' Data Registry. The admission sodium is used for statistical comparisons. The Hospital Clinical Governance approved the audit. Normonatraemia is defined as Serum Sodium (SNa) 135 to $144 \mathrm{mmol} / \mathrm{L}$, Hyponatraemia as <135 mmol/L and Hypernatraemic as > $145 \mathrm{mmol} / \mathrm{L}$.

\section{Results:}

The total study population was 98,078 . The mean age was 55.85 (+SD20.67) and 55.12\% were males and $44.88 \%$ were females. $45.26 \%$ were 60 years and older and $54.74 \%$ was less than 60 years of age. Hyponatraemia was observed in $5.05 \%$ on admission. The data showed that there were significant age differences between the different sodium groups with normal range being the youngest and those with severe hyponatraemia, the oldest $(p<0.0001)$. There were significant differences between gender and sodium levels with men having the highest levels in severe hyponatraemia category $(p<0.001)$. There were significant differences in mortality according to sodium level with lowest mortality in normal group and the highest death rate in hypernatraemic group $(p<0.001)$.

\section{Conclusion:}

Hyponatraemia as well as Hypernatraemia is associated with increased mortality compared to Normonatraemic group.

Acknowledgement:

Ms Penny Dhanjal, Medical Science Manager, Otsuka.

\begin{tabular}{|l|l|l|l|}
\hline Sex & Freq & Percent & Cum. \\
\hline F & 54,064 & 55.12 & 55.12 \\
\hline M & 44,014 & 44.88 & 100.00 \\
\hline Total & 98,078 & 100.00 & \\
\hline Sodium & Freq. & Percent & Cum. \\
\hline$<135$ & 4,954 & 5.05 & 5.05 \\
\hline $135-144$ & 89,224 & 90.97 & 96.02 \\
\hline$>=145$ & 3,900 & 3.98 & 100.00 \\
\hline Total & 98,078 & 100.00 & \\
\hline
\end{tabular}

\section{Summary of Age}

\begin{tabular}{|c|c|c|c|c|c|}
\hline \multicolumn{2}{|c|}{ Sodium mmol/LI } & \multicolumn{2}{|c|}{ Mean } & Std. Dev. & Freq. \\
\hline \multicolumn{2}{|l|}{$<135$} & \multicolumn{2}{|c|}{67.920065} & 18.599677 & 4954 \\
\hline \multicolumn{2}{|l|}{$135-144$} & \multicolumn{2}{|c|}{54.797039} & 20.515345 & 89224 \\
\hline \multicolumn{2}{|l|}{$>=145$} & \multicolumn{2}{|c|}{64.819487} & 19.840263 & 3900 \\
\hline \multicolumn{2}{|l|}{ Total } & \multicolumn{2}{|c|}{55.858429} & 20.677769 & 98078 \\
\hline agegrp & Frec & & Percent & Cum. & \\
\hline 1 & 14,8 & & 15.15 & 15.15 & $16-30$ \\
\hline 2 & 11,3 & & 11.57 & 26.72 & $31-40$ \\
\hline 3 & 13,7 & & 14.04 & 40.76 & $41-50$ \\
\hline 4 & 13,7 & & 13.98 & 54.74 & $51-60$ \\
\hline 5 & 15,7 & & 16.05 & 70.79 & $61-70$ \\
\hline 6 & 15,7 & & 16.03 & 86.82 & $71-80$ \\
\hline 7 & 12,9 & & 13.18 & 100.00 & $>80$ \\
\hline Total & 98,0 & & 100.00 & & \\
\hline
\end{tabular}

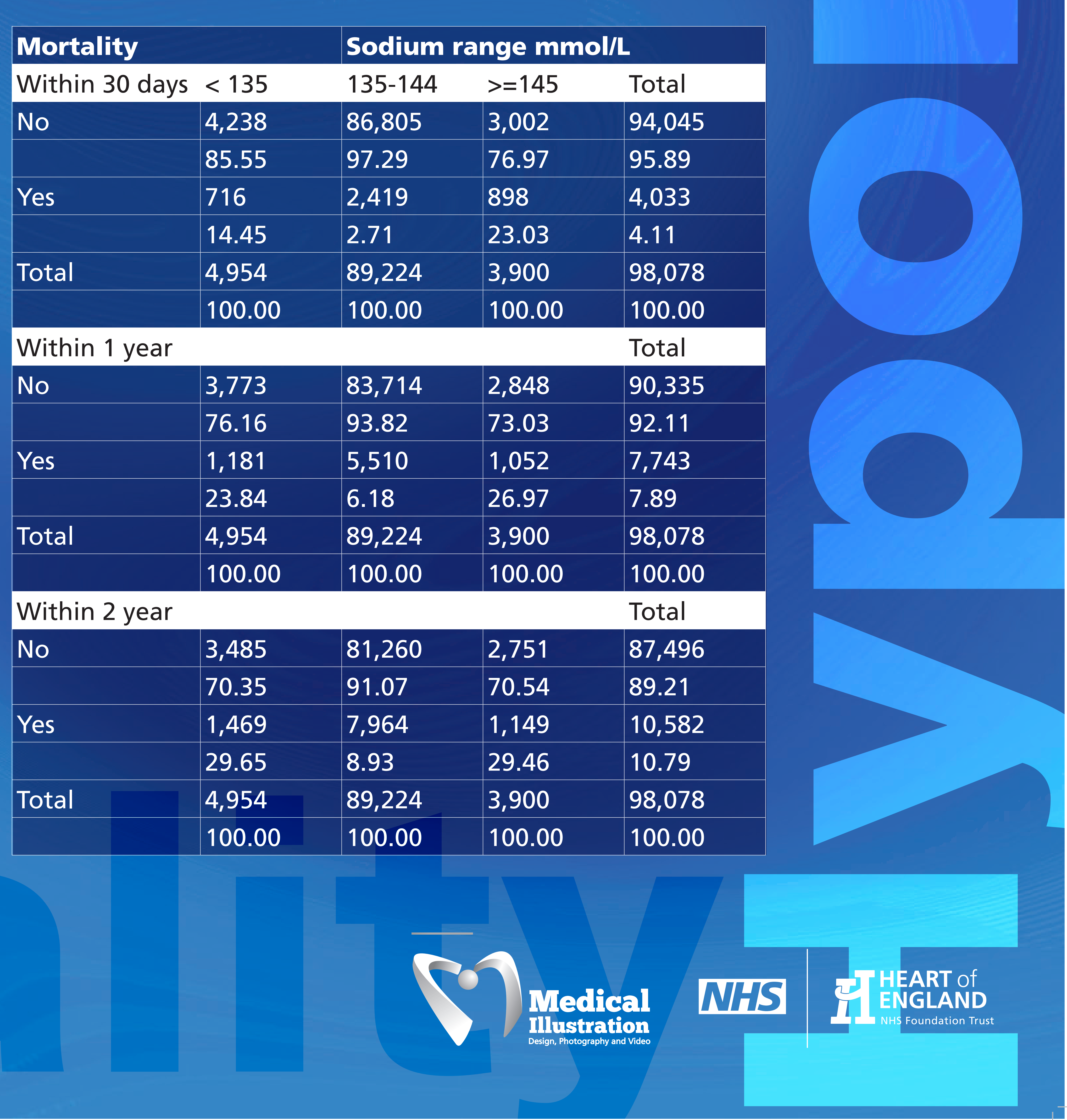

